\title{
Perumusan Strategi Operasi-Produksi Kosmetik (Studi Kasus PT ANI)
}

\author{
Operation-Production Strategy Formulation on Cosmetics (Case Study PT ANI)
}

\author{
Rizda Dwiyanti ${ }^{*}$, Musa Hubeis ${ }^{2}$, dan G Suprayitno ${ }^{3}$
}

\author{
${ }^{1}$ Program Diploma Institut Pertanian Bogor \\ Kampus IPB Cilibende. Jl. Kumbang No. 14, Bogor 16151 \\ ${ }^{2}$ Departemen Manajemen Fakultas Ekonomi dan Manajemen, IPB \\ Jl. Kamper Kampus IPB Dramaga Bogor 16680 \\ ${ }^{3}$ The Indonesian Institute for Corporate Governance \\ Jl. Radio Dalam Raya No 7C Kebayoran Baru Jakarta Selatan 12140
}

\begin{abstract}
ABSTRAK
Kebijakan Masyarakat Ekonomi ASEAN (MEA) mengakibatkan persaingan dalam industri kosmetik semakin meningkat. Kinerja operasi-produksi harus ditingkatkan agar menghasilkan kosmetik berstandar mutu ASEAN. Penelitian dilakukan pada perusahaan kosmetik skala menengah PT ANI, dengan tujuan menentukan misi dan objektif, strategi bisnis, strategi operasi berdasarkan prioritas tujuan kinerja fungsi operasi-produksi dan merumuskan strategi dan kebijakan pembangunan sumber daya dan proses operasi-produksi. Metode penelitian dengan deskriptif kualitatif dan alat analisis yang digunakan adalah analisis SWOT, matriks Strategic Factors Analysis Summary (SFAS), Matriks TOWS, Porter Generic Strategy, matriks strategi operasi serta Analytic Hierarchi Process (AHP) untuk pembobotan faktor strategi internal/eksternal dan penentuan prioritas strategi operasi-produksi. Berdasarkan hasil penelitian disimpulkan bahwa misi PT ANI memproduksi kosmetik perawatan wajah dan pribadi berbahan aktif alami yang aman dan bermutu, untuk menangkap pasar ceruk di dalam dan luar negeri. Strategi bisnis perusahaan adalah strategi bersaing fokus diferensiasi dan melayani pembuatan kosmetik perawatan wajah dan pribadi dengan varian dan volume sesuai kebutuhan pelanggan. Pengembangan dari sumber daya dan proses operasi-produksi diprioritaskan untuk memenuhi lima sasaran kinerja mutu $(0,454)$, keandalan $(0,270)$, fleksibilitas $(0,147)$, kecepatan $(0,082)$ dan biaya $(0,048)$. Disisi lain prioritas strategi operasi-produksi untuk memenuhi sasaran kinerja tersebut adalah strategi teknologi proses $(0,425)$, jaringan rantai pasok (0.235), kapasitas (0.206), pengembangan dan organisasi (0.133).
\end{abstract}

Kata kunci: kosmetik, strategi bisnis, strategi operasi-produksi

\section{ABSTRACT}

Policy ASEAN Economic Community (AEC) lead to competition in the cosmetics industry is increasing. Performance operation-production must be increased in order to produces cosmetic quality standards of ASEAN. Research conducted in medium-scale cosmetic companies PT ANI, with the aim of determining the mission and objectives, business strategy, operating strategy based on priority performance goals operation-production function and formulate strategy and policy for operationproduction resource and process development. Research methods with descriptive qualitative and and analysis tools used are SWOT analysis, SFAS matrix, Porter Generic Strategy, TOWS matrix, operations strategy matrix and the AHP for weighting internal/eksternal strategic factors and prioritize operationproduction strategy determination. Based on the results of this study concluded that PT ANI mission is produce facial and personal care cosmetics using natural active ingredients that are safe and good quality, to capture domestic and overseas niece market. The company's business strategy is competitive strategy of differentiation focus and serve the manufacture of face and personal care cosmetics with variants and volume according to customer requirements. The development of resources and operationproduction processes priority is to meet the five performance objectives, namely quality $(0,454)$, reliability $(0,270)$, flexibility $(0,147)$, speed $(0,082)$ and cost $(0,048)$. On the other hand operation-

\footnotetext{
$\left.{ }^{*}\right)$ Korespondensi:

Program Studi MPI, Sekolah Pascasarjana IPB, Jl. Raya Pajajaran Bogor; e-mail: rizda65@yahoo.com
} 
production strategic priority to meet the performance targets is a process technology $(0,425)$, supply chain network $(0,235)$, capacity $(0,206)$, the development and organization $(0,133)$.

Key words: business strategy, cosmetics, operation-production strategy

\section{PENDAHULUAN}

Produk kosmetika telah menjadi kebutuhan primer bagi masyarakat yang menembus seluruh lapisan usia baik wanita dan pria. Indonesia yang memiliki penduduk sekitar 250 juta jiwa, merupakan pasar produk kosmetika yang menjanjikan bagi perusahaan/produsen kosmetik serta akan mendorong pertumbuhan dan perkembangan industri kosmetika di Indonesia (Kemenperin 2014). Berdasarkan kompilasi dan estimasi duniaindustri.com, nilai pasar industri kosmetik mencakup produk kosmetik buatan lokal maupun impor ditunjukkan pada Gambar 1. Nilai pasar (market size) industri kosmetik di Indonesia tahun 2015 diestimasi tumbuh 9\% menjadi Rp64,3 triliun dibanding 2014 sebesar Rp59,03 triliun.

Dalam era MEA, tingkat persaingan dalam industri kosmetika akan semakin kuat. Usaha industri kosmetika skala kecil dan menengah (IKM) harus didorong untuk meningkatkan daya saing, agar dapat terus meningkatkan potensi pasar dan nilai penjualan. Peningkatan daya saing IKM kosmetik perlu diarahkan pada aspek mutu produk yang merupakan salah satu faktor kunci kesuksesan (KSF) dalam industri kosmetik. Produk bermutu dapat dicapai melalui penggunaan bahan-bahan yang baik dan layak serta proses produksi produk yang baik dan bersih (Tiyanto dan Mustamu, 2013).

Hal tersebut sejalan dengan Rencana Induk Pembangunan Industri Nasional (RIPIN) 20152035 (Kemenperin 2015), bahwa pembangunan industri kosmetik sebagai industri andalan mencakup modal dasar, yaitu faktor sumber daya yang digunakan dalam kegiatan industri untuk menghasilkan barang dan jasa serta dalam penciptaan nilai tambah atau manfaat yang tinggi. Modal dasar yang dimaksud diantaranya berupa sumber daya alam, sumber daya manusia, serta teknologi, inovasi, dan kreativitas.

Pengembangan IKM kosmetika juga harus mengacu kepada dua peraturan, pertama Peraturan Menteri Kesehatan Republik Indonesia Nomor 1175/MENKES/PER/VIII/2010 yang mempersyaratkan penerapan Cara Pembuatan Kosmetik Yang Baik (CPKB) pada setiap golongan industri, kedua Peraturan Menteri Kesehatan Republik Indonesia Nomor 1176/MENKES/PER/

VIII/2010 tentang notifikasi kosmetika, dimana setiap industri kosmetika yang berada di wilayah Indonesia yang telah memiliki izin produksi harus melakukan notifikasi sebelum produk kosmetika diedarkan.

\section{Total Nilai Penjualan \\ Industri Kosmetik di Indonesia}

$\leadsto$ Total Penjualan (triliun rupiah)

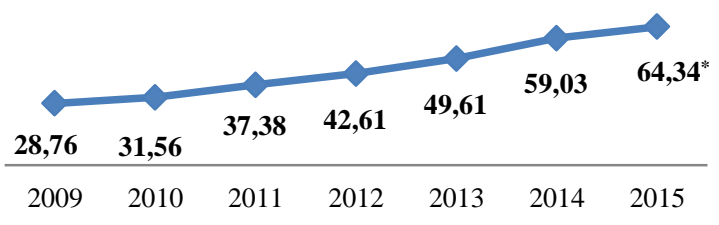

Sumber: www.duniaindustri.com

Gambar 1. Nilai penjualan industri kosmetik

Strategi operasi mencakup proses individu dan sangat memperhatikan proses perubahan total dari seluruh bisnis. Hal ini berkaitan dengan perubahan lingkungan kompetitif dan operasi apa yang harus dilakukan untuk memenuhi tantangan saat ini dan masa depan. Hal ini juga berkaitan dengan pembangunan jangka panjang dari sumber daya operasi dan proses sehingga dapat memberikan keuntungan yang berkelanjutan (Slack dan Lewis, 2011).

PT ANI merupakan perusahaan IKM kosmetik di kota Bogor yang memfokuskan pada pembuatan produk kosmetik perawatan wajah dan pribadi berbahan aktif alami. Proses produksi kosmetik saat ini menggunakan teknologi sederhana, serta bangunan pabrik dan sistem operasiproduksi beberapa unsurnya belum memenuhi persyaratan CPKB. Upaya perbaikan kinerja operasi-produksi perlu dilakukan perusahaan melalui penerapan strategi operasi yang tepat.

Tujuan penelitian ini adalah (1) Menentukan misi dan objektif perusahaan, (2) Menentukan strategi bisnis, (3) Menentukan strategi operasi berdasarkan prioritas tujuan kinerja fungsi operasi-produksi, (4) Merumuskan strategi dan kebijakan pembangunan sumber daya dan proses operasi-produksi. 


\section{METODE PENELITIAN}

Penelitian ini merupakan penelitian studi kasus pada PT ANI. Kerangka pemikiran penelitian ditunjukkan pada Gambar 2. Metode yang digunakan dalam penelitian adalah deskriptif dan kualitatif. Penggalian data dilakukan dengan teknik wawancara secara terstruktur dengan panduan dan pengisian kuesioner kepada sejumlah responden yang ditetapkan secara purposive, yaitu panel pakar yang mempunyai pengetahuan terkait perkembangan industri kosmetik nasional dan dari pihak manajemen PT ANI. Keterlibatan responden digunakan untuk proses membangkitkan (inisiasi) data faktor-faktor strategik internal dan eksternal perusahaan. Selain itu, penelitian memanfaatkan data sekunder berupa laporan manajemen maupun laporan publikasi lain terkait keragaman peubah kunci yang berpengaruh pada kinerja dan posisi strategik perusahaan. Hasil wawancara dan pengisian kuesioner maupun data sekunder tersebut akan dianalisis berdasarkan tahapantahapan perumusan strategi dan perangkat analisis.

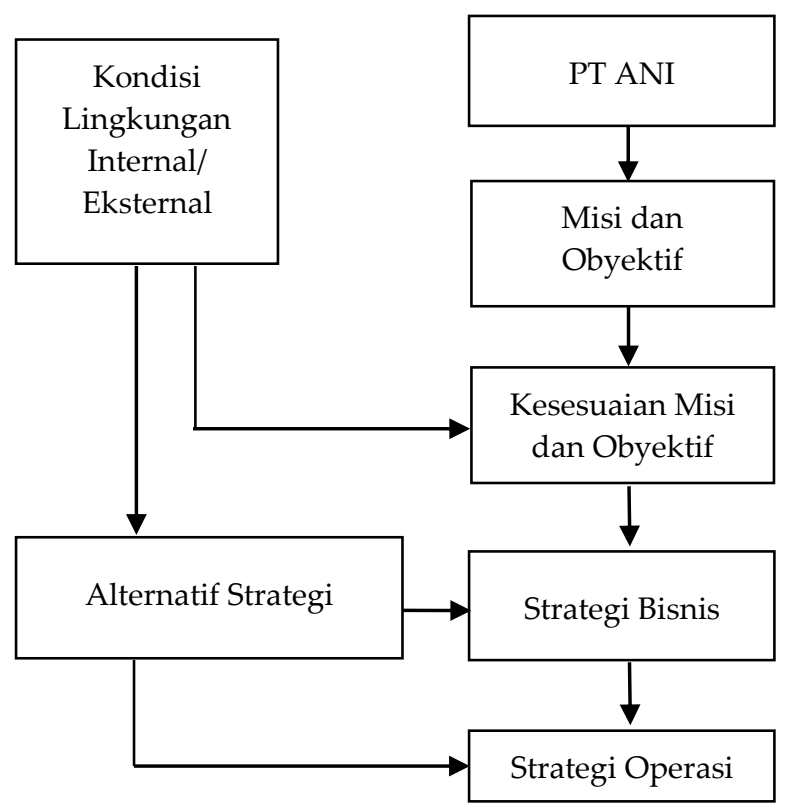

Gambar 2. Kerangka pemikiran penelitian

\section{HASIL DAN PEMBAHASAN}

PT ANI merupakan IKM kosmetik yang membuat produk sesuai dengan pesanan pelanggan (make to order), baik varian maupun volumenya. Perusahaan memiliki segmen pasar khusus (niece market) dan pelanggan PT ANI saat ini adalah beberapa hotel di wilayah Bogor, apotik, toko kosmetik, dokter Spk dan perusahaan MLM. PT ANI dalam menjalankan aktivitas sehari-hari dipimpin oleh seorang Direktur Utama (Dirut) dan satu orang Direktur Produksi dan R\&D yang juga merupakan pemegang saham perusahaan. Visi, misi dan tujuan perusahaan adalah:

a. Visi: Menjadi produsen produk kosmetik dan personal care terkemuka di Indonesia dan seluruh dunia.

b. Misi:

1) Menghasilkan produk aman dan bermutu sesuai peraturan perundang-undangan yang berlaku,

2) Menangkap target pasar khusus di dalam dan luar negeri,

3) Memberikan pemahaman mengenai manfaat dari berbagai bahan aktif alami pada personal care.

c. Tujuan:

1) Menyediakan informasi, pengetahuan dan berita tentang segala aspek produk personal care.

2) Menggunakan merek sendiri untuk menjual ke pasar lokal dan pasar internasional.

3) Menyediakan forum Nasional dan Internasional untuk saling bertukar informasi dan gagasan mengenai personal care.

4) Membuka lapangan pekerjaan dan mengurangi kemiskinan.

5) Memberikan tambahan keahlian khsusus kepada tenaga teknis yang pada awalnya tidak memiliki keahlian dalam memproduksi sediaan kosmetik.

\section{Sumber Daya}

Menurut Fleisher dan Bensoussan dalam Tiyanto dan Mustamu (2013), sumber daya merupakan asset dan kemampuan yang dimiliki perusahaan guna menghasilkan output. Sumber daya merupakan modal untuk dapat bertahan dalam lingkungan persaingan yang semakin ketat, serta sebagai modal untuk berkembang mewujudkan visi dan misi perusahaan.

Sumber daya berwujud yang dimiliki PT ANI adalah sumber daya manusia (SDM), finansial serta sarana dan prasarana produksi. Sumber daya finansial menjadi unsur yang penting dalam penentuan keputusan strategik perusahaan. Perusahaan menggunakan dana cashflow, baik untuk operasional sehari-hari mau- 
pun untuk pengembangan sarana dan prasarana produksi. Manager keuangan mengelola seluruh keuangan perusahaan dengan menggunakan program excell.

Fasilitas produksi perusahaan, diantaranya bangunan pabrik beserta kantor seluas $\pm 1.000 \mathrm{~m}^{2}$, kendaraan untuk mendistribusikan material/ produk jadi dan peralatan produksi. Bangunan pabrik terdiri dari ruang pengemasan, gudang produk jadi, gudang bahan baku, dan ruang produksi berupa area penimbangan, pencampuran, pemasakan dan pencetakan. Peralatan produksi utama adalah tangki pencampur berpengaduk otomatis atau manual dan beberapa peralatan pendukung yang masih sederhana, seperti kompor, timbangan, wadah bahan, cetakan sabun dan alat pemotong sabun. Tangki pemanas berpengaduk manual digunakan jika aliran listrik PLN mati.

Proses produksi semua varian produk dijalankan menggunakan teknologi sederhana dan tidak memerlukan level kompetensi tinggi. Oleh karena itu, perusahaan hanya mengutamakan faktor mental dalam proses rekrutmen karyawan bagian produksi. Karyawan PT ANI terdiri dari 30 karyawan tetap (Tabel 1) dan karyawan kontrak yang jumlahnya selalu berubah tergantung beban pekerjaan di bagian produksi dan pengemasan.

Selain sumber daya berwujud, perusahaan yang telah berdiri hampir delapan tahun mampu menciptakan sumber daya tidak berwujud yang banyak dipertimbangkan pelanggan. Sumber daya tidak berwujud tersebut berupa citra dan reputasi baik di mata pelanggan, jaringan website adevnatural.com, pengalaman di bidang pemasaran, serta keahlian dalam pengembangan formula dan proses produksi kosmetik.

\section{Strategi Operasi Existing}

Strategi pada empat area keputusan operasi yang pernah atau saat ini dijalankan perusahaan adalah:

\section{Strategi Kapasitas}

Keputusan jangka panjang pernah dilakukan perusahaan saat memindahkan lokasi pabrik pada tahun 2011, yaitu dari kampus IPB Baranangsiang ke lokasi pabrik saat ini. Selain itu, meningkatkan kapasitas produksi pada tahun 2012 dengan menambah satu buah tangki pemanas berkapasitas $300 \mathrm{~kg}$. Keputusan jangka pendek terkait kapasitas dilakukan perusahaan saat harus merubah tingkat kapasitas yang disebabkan adanya perubahan tingkat pesanan, yaitu penambahan/pengurangan karyawan kontrak atau shift kerja di bagian produksi. Perubahan tingkat kapasitas dengan cara ini tidak mahal dan dapat dilakukan secara cepat.

Tabel 1. Jumlah tenaga kerja tetap PT ANI

\begin{tabular}{lcc}
\hline \multicolumn{1}{c}{ Jabatan } & Pendidikan & $\begin{array}{c}\text { Jumlah TK } \\
\text { (orang) }\end{array}$ \\
\hline $\begin{array}{l}\text { Dewan Komisaris } \\
\text { Direktur Utama/ }\end{array}$ & S3 2 \\
$\begin{array}{l}\text { Marketing } \\
\text { Direktur Produksi/ R }\end{array}$ & S2 & 1 \\
\& D & Non sarjana & 1 \\
Administrasi & Non sarjana & 1 \\
Keuangan & Non sarjana & 1 \\
Administrasi Umum & 8 \\
$\begin{array}{l}\text { Asisten Produksi } \\
\text { Tenaga kerja bagian }\end{array}$ & Non sarjana & 13 \\
$\begin{array}{l}\text { Produksi } \\
\text { Tenaga kerja bagian } \\
\text { pengemasan }\end{array}$ & Non sarjana & 1 \\
$\begin{array}{l}\text { Cleaning service } \\
\text { Security }\end{array}$ & Non sarjana & 1 \\
\hline \multicolumn{1}{c}{ Total } & Non sarjana & 30 \\
\hline
\end{tabular}

Sumber: PT ANI (2015).

\section{Strategi Jaringan Pasokan}

Strategi ini dilakukan perusahaan, terutama pada aktivitas pembelian bahan baku, bahan pendukung dan bahan kemasan yang dibutuhkan untuk membuat produk yang dipesan pelanggan akhir. Secara umum, untuk menjamin kesesuaian mutu dan waktu pengiriman pasokan, serta untuk mendapatkan biaya transaksi yang rendah, perusahaan menjalin kemitraan dengan beberapa pemasok atas dasar kepercayaan.

Khusus untuk bahan aktif dan parfum impor dengan waktu kedatangan pesanan 2-3 bulan, perusahaan menggunakan beberapa pemasok setia dan membuat kesepakatan tidak tertulis yang menyatakan bahwa pemasok tidak menjual bahan tersebut kepada produsen kosmetik lain, sejauh perusahaan dapat mempertahankan jumlah pesanan minimum yang telah ditentukan (> $100 \mathrm{~kg}$ per tahun). Jika tingkat kebutuhan bahan besar, perusahaan juga akan menyampaikan perkiraan kebutuhan dalam 1 tahun kepada pemasok dan selanjutnya pemasok akan membuat PO beserta stok pengaman sesuai keperluan.

Untuk pembelian bahan baku berupa produk komoditas, perusahaan menggunakan strategi banyak pemasok (many supplier). Dalam menjalankan strategi ini, masih ditemukan ketidaksesuain mutu yang dapat menyebabkan gangguan pada proses produksi. 


\section{Strategi Teknologi Proses}

Proses produksi kosmetik sebagian besar dilakukan secara manual, kecuali pada proses pencampuran formula telah menggunakan tangki berpengaduk otomatis. Teknologi proses ini menimbulkan banyak pemborosan di setiap tahapan proses produksi.

\section{Strategi Pengembangan dan Organisasi}

Untuk mengarahkan perbaikan operasi, perusahaan belum melakukan pengukuran kinerja yang terorganisir. Perbaikan kinerja pada aktivitas proses produksi dilakukan atas dasar hasil pengamatan terhadap produk cacat atau jumlah produk yang terbuang (scrap) dan pemborosan yang terjadi sepanjang proses, walaupun data tersebut belum terdokumentasi. Perusahaan juga pernah melakukan pengukuran produktivitas sesaat berkenaan dengan kemampuan pengemasan produk harian, jumlah produksi per hari dan jumlah potongan sabun per hari.

\section{Analisis Lingkungan}

\section{Analisis Lingkungan Internal}

Analisis terhadap lingkungan internal perusahaan bertujuan mengidentifikasi sejumlah faktor kekuatan dan kelemahan yang terdapat pada sumber daya dan proses bisnis internal yang dimiliki perusahaan. Pendekatan Resource-based View of the Firm melihat sumber daya internal adalah bagian yang paling penting bagi perusahaan dalam menghadapi persaingan. Wandrial (2011) melakukan analisis lingkungan internal perusahaan menggunakan Value Chain Analysis dikombinasikan dengan Resource Based View of The Firm dan VRIO Framework.

\section{Analisis Rantai Nilai dari Porter (Porter's Value Chain Analysis)}

Penelaahan secara sistematik terhadap aktivitas penciptaan nilai di setiap aktivitas perusahaan akan memberikan pemahaman lebih baik terhadap kekuatan dan kelemahan yang dimiliki perusahaan. Berdasarkan Porter, perbedaan dengan rantai nilai kompetitor merupakan sumber kunci keunggulan bersaing (Wheelen dan Hunger, 2012).

Michael E Porter mengembangkan model rantai nilai untuk sektor manufaktur dengan lima aktivitas utama dan empat aktivitas pendukung (Acharyulu et al., 2015).

\section{a. Aktivitas Utama}

Aktivitas utama merupakan kegiatan yang terlibat langsung dalam proses konversi bahan baku menjadi produk akhir termasuk penerimaan bahan baku dasar dari pemasok dan pemasaran output/produk kepada pelanggan (Acharyulu et al., 2015).

1) Pemasaran dan Penjualan (Marketing and Sales)

Aktivitas pemasaran dan penjualan kosmetik merupakan tanggungjawab Direktur Utama (Dirut) yang dibantu beberapa tenaga pemasaran freelance. Media promosi utama yang digunakan adalah website perusahaan adevnatural.com dan media internet lainnya seperti online shop. Promosi juga dilakukan oleh tenaga pemasaran freelance, khususnya untuk memperluas pasar dokter Spk, salon dan spa.

\section{2) Layanan Pelanggan}

Umumnya pesanan terjadi setelah pelanggan baru mengenal PT ANI melalui tayangan website dan melakukan transaksi secara langsung di lokasi pabrik. Dirut akan melayani pelanggan dan mengklarifikasi contoh kosmetik yang dibawa untuk dibuatkan formulanya. Dalam pengembangan formula harus memperhatikan ketersediaan bahan baku dan teknologi, agar scaleup (produksi) dapat segera dilakukan. Pelanggan akan mengeluarkan PO setelah spesifikasi dan harga produk yang ditawarkan sesuai.

\section{3) Pengendalian Logistik dalam Perusahaan (Inbound Logistic)}

Aktivitas pengendalian logistik pada PT ANI mencakup aktivitas pengendalian bahan baku utama, bahan pendukung dan bahan kemasan yang digunakan dalam proses produksi kosmetik. Semua material tersebut diletakkan dalam satu gudang raw material (GRM), tetapi disusun secara terpisah berdasarkan jenis material. Tata letak GRM cukup baik, sehingga pengambilan dan pengecekan stok dapat dilakukan dengan mudah.

Untuk mengendalikan jumlah stok material di GRM, perusahaan menggunakan strategi persediaan dengan cara mengatur waktu dan jumlah pesanan. Pemesanan ulang akan dilakukan, jika jumlah stok material berada di bawah stok minimum. Stok minimum merupakan prakiraan kebutuhan material selama dua minggu ke depan yang dihitung berdasarkan data pesanan produk dari bagian pemasaran.

Untuk mendukung akurasi pencatatan keluar-masuk material, digunakan program komputer MS Excel. Selanjutnya data stok setiap material akan diverifikasi setiap bulan melalui pengecekan dan penghitungan fisik meterial yang tersedia di gudang. 


\section{4) Operasi}

Aktivitas operasi PT ANI adalah pembuatan produk kosmetik berdasarkan purchase order (PO) yang diterima. Proses dilanjutkan ke tahap pembuatan formula dan penjadwalan produksi. Teknologi proses dan fasilitas produksi yang digunakan sama untuk semua varian produk, baik sabun, lotion, scrub maupun produk kosmetik lainnya. Proses produksi utama untuk semua varian produk terdiri dari proses penimbangan bahan baku, pencampuran dan pemanasan bahan kosmetik pada tangki pemanas berpengaduk dengan kapasitas $250 \mathrm{~kg}$ atau $100 \mathrm{~kg}$, pencetakan (khusus untuk sabun padat), pendinginan dan proses pengisian/pengemasan. Untuk produk sabun padat dikemas menggunakan kemasan primer dan sekunder dari bahan karton, sedangkan untuk produk sabun transparan atau kosmetik berbentuk cair, lotion atau gel dikemas menggunakan berbagai bentuk kemasan primer dari bahan plastik.

Fasilitas produksi diatur pada tempat (job shop) berdasarkan aktivitas atau proses untuk membuat beragam produk kosmetik sesuai pesanan pelanggan. Pengaturan fasilitas yang terfokus pada proses ini akan menyediakan tingkat produksi dengan fleksibilitas yang tinggi, dimana produk dapat berpindah sesaat diantara proses-proses yang ada.

Pemeliharaan terhadap peralatan/fasilitas produksi sangat diperlukan untuk menjamin kontinuitas produksi serta mutu produk yang dihasilkan. Pencucian tangki dilakukan setiap kali selesai pembuatan produk.

\section{5) Logistik Luar Perusahaan}

Aktivitas pengiriman produk jadi dari pabrik ke lokasi pelanggan ditangani oleh perusahaan sendiri, dengan menggunakan kendaraan milik perusahaan atau kendaraan sewa untuk pengiriman barang luar jabodetabek.

\section{b. Aktivitas Pendukung}

\section{1) Infrastruktur Perusahaan}

Infrastruktur PT ANI yang sangat penting dalam mendukung kelancaran aktivitas primer adalah website perusahaan, dana cashflow, koordinasi antara bagian pemasaran, $R \mathcal{E} D$, produksi dan keuangan dalam pengembangan produk baru dan sistem notifikasi on-line BPOM.

\section{2) Manajemen SDM}

Aktivitas manajemen SDM ditujukan untuk pencapaian target produksi dan efisiensi biaya, mencakup perekrutan dan merumahkan karyawan, sistem pengupahan, pemberian reward and punishment, serta penjadwalan kerja.

Untuk sistem pengupahan yang berlaku untuk karyawan tetap dan tidak tetap adalah:

a. Perusahaan mengatur dan menerapkan sistem pemberian upah yang layak bagi pekerja yang disesuaikan dengan golongan, status, jabatan, keahlian dan prestasi.

b. Besarnya upah terendah yang diberikan kepada pekerja tidak boleh kurang dari ketentuan minimum yang berlaku sesuai dengan peraturan yaitu Upah Minimum Propinsi (UMP).

c. Pembayaran gaji kepada karyawan dilakukan sekali dalam sebulan, yaitu pada setiap akhir bulan. Bonus yang diberikan kepada karyawan berupa Tunjangan Hari Raya (THR) dan bonus akhir tahun. Untuk karyawan tetap diberikan uang tunjangan transportasi.

Untuk penjadwalan kerja (Tabel 2), perusahaan menerapkan dua kategori jam kerja yang berbeda antara karyawan shift dan non-shift.

Tabel 2. Jadwal kerja

\begin{tabular}{llc}
\hline \multicolumn{1}{c}{ Karyawan } & Hari Kerja & \multicolumn{1}{c}{ Jam Kerja } \\
\hline Non-shift & Senin - Jumat & $07.00-16.30$ \\
& Sabtu & $08.00-13.00$ \\
Shift & Senin - Jumat & $07.30-15.30$ (shift 1) \\
& & $15.30-23.30$ (shift 2) \\
& & \\
& Sabtu & $08.00-13.00$ (shift 1) \\
& & $13.00-18.00$ (shift 2)
\end{tabular}

Sumber: PT ANI (2015).

\section{3) Pengembangan Teknologi}

Aktivitas pengembangan teknologi terutama pada teknologi produksi yang dilakukan secara bertahap dengan mempertimbangkan dana cashflow yang tersedia. Aktivitas pengembangan produk terutama pada aspek formula, bentuk, warna dan kemasan dilakukan oleh tim $R \mathcal{E} D$ perusahaan pada laboratorium yang sederhana.

\section{4) Pembelian}

Aktivitas pembelian terutama untuk menyediakan bahan baku, bahan pendukung dan bahan kemasan, dengan menggunakan beberapa pemasok. Perusahaan akan memberikan spesifikasi permintaan penawaran kepada pemasok dan umumnya pesanan akan jatuh ke pihak dengan penawaran harga terendah. Pesanan berikutnya dapat berpindah kepada pihak lain, jika perusahaan mendapatkan penawaran lebih baik untuk harga, mutu, sistem pembayaran dan juga 
kemampuan pengiriman. Perusahaan belum melakukan pengujian laboratorium terhadap mutu material yang diterima, tetapi ketidaksesuaian mutu material dapat diketahui pada saat produksi berlangsung.

\section{Analisis VRIO}

Analisis VRIO (Tabel 3) merupakan penelaahan lebih lanjut terhadap sumber daya dan kemampuan PT ANI, apakah memberikan kontribusi secara riil terhadap kemampuan bersaing perusahaan saat ini ataukah masih bersifat potensial.

Penjelasan dari masing-masing kompetensi adalah;

a. Tim pemasaran dipimpin Direktur Marketing/ Dirut berpengalaman dan memiliki keterampilan di bidang pemasaran, serta berlatarbelakang pendidikan Strata 2 (S2).

b. Adanya keterbatasan anggaran biaya pemasaran, menjadikan situs internet perusahaan dan media sosial merupakan alat pemasaran penting. Situs internet perusahaan harus selalu diperbarui guna memenuhi kebutuhan konsumen.

c. Sumber daya keuangan berasal dari dana cashflow, dikelola dengan baik untuk modal produksi, operasional perusahaan dan pengembangan sumber daya fisik yang penting dalam peningkatan daya saing.

d. Pabrik memiliki skala produksi rumah tangga dan teknologi produksi sederhana. Pengaturan tata letak fasilitas produksi terfokus pada proses, dimana produk dapat berpindah sesaat diantara proses-proses yang ada dalam menghasilkan produk kosmetik pesanan pelanggan.

e. Hubungan kemitraan yang kuat dengan beberapa pemasok, untuk memperoleh bahan baku dan kemasan dengan penawaran terbaik dari aspek harga, mutu, sistem pembayaran serta kemampuan pengiriman.

f. Tim R \& D dipimpin oleh Direktur R \& D berlatar belakang pendidikan S2 di bidang industri dan memiliki pengetahuan bahan kosmetik yang baik.

\section{Analisis Lingkungan Eksternal}

Analisis lingkungan eksternal bertujuan mengidentifikasi faktor peluang dan ancaman $(O-$ $T$ ) yang memengaruhi aktivitas PT ANI. Sulistyo et al. (2011) menggunakan dua alat analisis dalam melakukan pengamatan lingkungan eksternal, yaitu analisis PEST untuk memonitor tren industri kosmetik dalam lingkungan sosial dan Porter Five Force untuk mengidentifikasi ancaman yang berasal dari lima kekuatan dalam lingkungan industri kosmetik. Hasil analisis lingkungan eksternal ditunjukkan pada Tabel 4.

Tabel 3. Hasil analisis VRIO

\begin{tabular}{|c|c|c|c|}
\hline No. & Kompetensi & VRIO & Kategori \\
\hline 1. & $\begin{array}{l}\text { Tim pemasaran } \\
\text { andal }\end{array}$ & $\begin{array}{l}\text { Value, } \\
\text { Rare, } \\
\text { Imitate }\end{array}$ & $\begin{array}{l}\text { Kekuatan dan } \\
\text { kompetensi } \\
\text { khusus jangka } \\
\text { panjang }\end{array}$ \\
\hline 2. & $\begin{array}{l}\text { Situs internet } \\
\text { perusahaan }\end{array}$ & Value & $\begin{array}{l}\text { Kompetitif } \\
\text { paritas }\end{array}$ \\
\hline 3. & $\begin{array}{l}\text { Kecepatan } \\
\text { Pengembangan } \\
\text { produk }\end{array}$ & $\begin{array}{l}\text { Value, } \\
\text { Rare, } \\
\text { Imitate }\end{array}$ & $\begin{array}{l}\text { Kekuatan dan } \\
\text { kompetensi } \\
\text { khusus jangka } \\
\text { panjang }\end{array}$ \\
\hline 4. & $\begin{array}{l}\text { Tim } R \mathcal{E} D \text { yang } \\
\text { kuat dan } \\
\text { berpengalaman } \\
\text { dalam desain } \\
\text { produk dan proses }\end{array}$ & $\begin{array}{l}\text { Value, } \\
\text { Rare, } \\
\text { Imitate }\end{array}$ & $\begin{array}{l}\text { Kekuatan dan } \\
\text { kompetensi } \\
\text { khusus jangka } \\
\text { panjang }\end{array}$ \\
\hline 5. & $\begin{array}{l}\text { Hubungan } \\
\text { kemitraan yang } \\
\text { kuat dengan } \\
\text { beberapa pemasok } \\
\text { bahan baku }\end{array}$ & $\begin{array}{l}\text { Value, } \\
\text { Rare, } \\
\text { Imitate }\end{array}$ & $\begin{array}{l}\text { Kekuatan dan } \\
\text { kompetensi } \\
\text { khusus jangka } \\
\text { panjang }\end{array}$ \\
\hline 6. & $\begin{array}{l}\text { Prosedur } \\
\text { pengendalian mutu } \\
\text { bahan baku }\end{array}$ & Value & $\begin{array}{l}\text { Kompetitif } \\
\text { paritas }\end{array}$ \\
\hline 7. & $\begin{array}{l}\text { Sumber daya } \\
\text { keuangan: dana } \\
\text { cashflow }\end{array}$ & Value & $\begin{array}{l}\text { Kompetitif } \\
\text { paritas }\end{array}$ \\
\hline 8. & $\begin{array}{l}\text { Kehandalan } \\
\text { fasilitas produksi }\end{array}$ & Value & $\begin{array}{l}\text { Kompetitif } \\
\text { paritas }\end{array}$ \\
\hline 9. & $\begin{array}{l}\text { Efektivitas } \\
\text { pengendalian mutu } \\
\text { fase prosesing }\end{array}$ & Value & $\begin{array}{l}\text { Kompetitif } \\
\text { paritas }\end{array}$ \\
\hline 10. & $\begin{array}{l}\text { Level kapasitas } \\
\text { produksi }\end{array}$ & Value & $\begin{array}{l}\text { Kompetitif } \\
\text { paritas }\end{array}$ \\
\hline 11. & $\begin{array}{l}\text { Kapabilitas } \\
\text { manufaktur yang } \\
\text { fleksibel }\end{array}$ & Value & $\begin{array}{l}\text { Kompetitif } \\
\text { paritas }\end{array}$ \\
\hline 12. & $\begin{array}{l}\text { Efisiensi dan } \\
\text { efektivitas } \\
\text { kebijakan } \\
\text { personalia }\end{array}$ & Value & $\begin{array}{l}\text { Kompetitif } \\
\text { paritas }\end{array}$ \\
\hline
\end{tabular}

\section{Analisis Faktor Strategik}

Analisis SWOT merupakan analisis faktorfaktor strategik (Strenghs, Weaknesses, Opportunities, and Threats) dari perusahaan. Berdasarkan analisis SWOT teridentifikasi kompetensi langka (distinctive competence) perusahaan, yaitu keahlian tertentu dan sumber daya yang dimiliki perusahaan serta cara unggul yang digunakan. 
Selain itu, akan teridentifikasi pula beberapa peluang yang tidak dapat diraih karena tidak tersedianya sumber daya (Wheelen dan Hunger, 2012).

Tabel 4. Ringkasan peluang dan ancaman

\begin{tabular}{|c|c|}
\hline Peluang & Ancaman \\
\hline $\begin{array}{l}\text { Peningkatan PDB } \\
\text { Nasional -pertumbuhan } \\
\text { sektor PKRT }\end{array}$ & $\begin{array}{l}\text { Persyaratan izin } \\
\text { produksi industri } \\
\text { kosmetik }\end{array}$ \\
\hline $\begin{array}{l}\text { Tren gaya hidup } \\
\text { masyarakat Indonesia }\end{array}$ & $\begin{array}{l}\text { Inflasi berdampak pada } \\
\text { penurunan tingkat } \\
\text { penjualan produk } \\
\text { kosmetik alami }\end{array}$ \\
\hline $\begin{array}{l}\text { Pertumbuhan jumlah } \\
\text { penduduk Indonesia }\end{array}$ & $\begin{array}{l}\text { Pelemahan nilai tukar } \\
\text { rupiah terhadap dolar } \\
\text { Amerika mempengaruhi } \\
\text { harga bahan baku impor }\end{array}$ \\
\hline $\begin{array}{l}\text { Perkembangan teknologi } \\
\text { dan sistem informasi }\end{array}$ & $\begin{array}{l}\text { Perjanjian CAFTA } \\
\text { menyebabkan maraknya } \\
\text { peredaran produk } \\
\text { kosmetik impor dengan } \\
\text { harga lebih murah }\end{array}$ \\
\hline $\begin{array}{l}\text { Perkembangan teknologi } \\
\text { proses produksi }\end{array}$ & $\begin{array}{l}\text { Perubahan UU } \\
\text { Ketenagakerjaan dengan } \\
\text { menaikkan UMR sangat } \\
\text { mempengaruhi HPP }\end{array}$ \\
\hline $\begin{array}{l}\text { Kesepakatan pasar } \\
\text { tunggal ASEAN } \\
\text { membuka peluang } \\
\text { ekspor produk kosmetik } \\
\text { nasional ke beberapa } \\
\text { negara anggota ASEAN }\end{array}$ & $\begin{array}{l}\text { Kebijakan pemerintah } \\
\text { menaikkan harga BMM } \\
\text { berdampak pada } \\
\text { kanaikkan beberapa } \\
\text { komponen biaya } \\
\text { produksi }\end{array}$ \\
\hline $\begin{array}{l}\text { PERMENKES dan } \\
\text { Peraturan Kepala BPOM } \\
\text { terkait CPKB yang } \\
\text { mengacu pada ACD }\end{array}$ & $\begin{array}{l}\text { Persyaratan sertifikat } \\
\text { CPKB membutuhkan } \\
\text { investasi jangka panjang } \\
\text { cukup besar }\end{array}$ \\
\hline $\begin{array}{l}\text { Dukungan pemerintah } \\
\text { pada IKM kosmetik, } \\
\text { berupa bimbingan teknis } \\
\text { dan denah pabrik sesuai } \\
\text { CPKB }\end{array}$ & $\begin{array}{l}\text { Ancaman pendatang } \\
\text { baru dengan kekuatan } \\
\text { modal cukup besar }\end{array}$ \\
\hline
\end{tabular}

Matriks SFAS meringkas faktor-faktor strategik dengan mengkombinasikan faktor-faktor eksternal pada tabel EFAS (External Factor Analysis Summary) dengan faktor-faktor internal pada tabel IFAS (Internal Factor Analysis Summary). Matriks SFAS (Strategic Factors Analysis Summary) membantu pengambil keputusan dengan meringkas faktor-faktor stratejik menjadi sepuluh faktor, dengan cara memperhatikan bobot pada masing-masing faktor. Faktor-faktor EFAS dan IFAS dengan bobot tertinggi akan muncul pada matriks SFAS (Wheelen dan Hunger, 2012).
Faktor lingkungan internal penting (kekuatan-kelemahan) perusahaan diringkas ke dalam bentuk tabel IFAS (Tabel 5) dan faktorfaktor lingkungan eksternal penting (peluangancaman) ke dalam bentuk tabel EFAS (Tabel 6). Analisis dilanjutkan dengan membuat matriks SFAS (Tabel 7), yaitu meringkas faktor-faktor strategik menjadi delapan faktor dengan cara memperhatikan bobot tertinggi dari masingmasing faktor yang terdapat pada Tabel IFAS dan EFAS.

Tabel 5. Faktor IFAS

\begin{tabular}{|c|c|c|c|}
\hline Faktor Internal & Bobot & Rating & skor \\
\hline \multicolumn{4}{|l|}{ Kekuatan } \\
\hline S1: Tim Pemasaran handal & 0,05 & 4 & 0,20 \\
\hline $\begin{array}{l}\text { S2: Kecepatan } \\
\text { pengembangan produk }\end{array}$ & 0,07 & 4 & 0,28 \\
\hline $\begin{array}{l}\text { S3: Tim R \& D } \\
\text { berpengalaman }\end{array}$ & 0,33 & 3 & 0,99 \\
\hline $\begin{array}{l}\text { S4: Hubungan kemitraan } \\
\text { dengan beberapa pemasok }\end{array}$ & 0,25 & 3 & 0,75 \\
\hline \multicolumn{4}{|l|}{ Kelemahan } \\
\hline $\begin{array}{l}\text { W1: Kehandalan fasilitas } \\
\text { produksi }\end{array}$ & 0,03 & 2 & 0,06 \\
\hline $\begin{array}{l}\text { W2: Prosedur pengendalian } \\
\text { mutu bahan baku }\end{array}$ & 0,15 & 2 & 0,30 \\
\hline $\begin{array}{l}\text { W3: Efektivitas } \\
\text { pengendalian mutu fase } \\
\text { prosesing }\end{array}$ & 0,10 & 1 & 0,10 \\
\hline W4: Level kapasitas produksi & 0,02 & 1 & 0,02 \\
\hline Total Skor & 1,00 & & 2,70 \\
\hline
\end{tabular}

Tabel 6. Faktor EFAS

\begin{tabular}{lccc}
\hline Faktor Eksternal & Bobot & Rating & skor \\
\hline $\begin{array}{l}\text { Peluang } \\
\text { O1: Peningkatan PDB }\end{array}$ & 0,07 & 3 & 0,21 \\
$\begin{array}{l}\text { Nasional - pertumbuhan } \\
\text { sektor PKRT }\end{array}$ & & & \\
$\begin{array}{l}\text { O2: Pertumbuhan jumlah } \\
\text { penduduk }\end{array}$ & 0,10 & 4 & 0,40 \\
$\begin{array}{l}\text { O3: Tren gaya hidup } \\
\text { masyarakat }\end{array}$ & 0,26 & 4 & 1,04 \\
$\begin{array}{l}\text { O4: Perkembangan } \\
\text { teknologi komputer dan }\end{array}$ & 0,23 & 3 & 0,69 \\
$\begin{array}{l}\text { internet } \\
\text { Ancaman }\end{array}$ & & & \\
$\begin{array}{l}\text { T1: Persyaratan izin industri } \\
\text { kosmetik } \\
\text { T2: Pelemahan nilai tukar }\end{array}$ & 0,24 & 1 & 0,24 \\
rupiah terhadap $\$$ US & 0,05 & 2 & 0,10 \\
$\begin{array}{l}\text { T3: Tingkat inflasi } \\
\text { T4: Persyaratan sertifikat } \\
\text { CPKB }\end{array}$ & 0,03 & 1 & 0,03 \\
\hline Total Skor & 0,02 & 1 & 0,02 \\
\hline & 1,00 & & 2,73 \\
\hline
\end{tabular}


Tabel 7. Faktor SFAS

\begin{tabular}{lccc}
\hline Faktor Strategik & Bobot & Rating & Skor \\
\hline $\begin{array}{l}\text { S3: Tim R \& D yang kuat } \\
\text { dan berpengalaman dalam } \\
\text { desain produk dan proses }\end{array}$ & 0,33 & 3 & 0,99 \\
$\begin{array}{l}\text { S4: Hubungan kemitraan } \\
\text { yang kuat dengan }\end{array}$ & 0,16 & 3 & 0,48 \\
$\begin{array}{l}\text { beberapa pemasok } \\
\text { W2: Prosedur }\end{array}$ & 0,05 & 4 & 0,20 \\
$\begin{array}{l}\text { pengendalian mutu bahan } \\
\text { baku }\end{array}$ & & & \\
$\begin{array}{l}\text { W3: Efektivitas } \\
\text { pengendalian mutu fase } \\
\text { prosesing }\end{array}$ & 0,03 & 3 & 0,09 \\
$\begin{array}{l}\text { O3: Tren gaya hidup } \\
\text { masyarakat Indonesia }\end{array}$ & 0,23 & 4 & 0,92 \\
$\begin{array}{l}\text { O4: Perkembangan } \\
\text { teknologi informasi } \\
\text { (komputer dan internet) }\end{array}$ & 0,07 & 3 & 0,21 \\
$\begin{array}{l}\text { T1: Persyaratan izin } \\
\text { industri kosmetik }\end{array}$ & 0,11 & 4 & 0,44 \\
$\begin{array}{l}\text { T2: Pelemahan nilai tukar } \\
\text { rupiah terhadap \$US }\end{array}$ & 0,02 & 3 & 0,06 \\
\hline \begin{tabular}{l} 
Total Skor \\
\hline
\end{tabular} & 1,00 & & 3,39 \\
\hline
\end{tabular}

Berdasarkan faktor SFAS, dapat disimpulkan hal berikut:
1. Misi PT ANI menghasilkan produk kosmetik dan personal care berbahan aktif alami yang aman dan bermutu untuk menangkap target pasar khusus di dalam dan luar negeri, masih selaras dengan lingkungan internal dan eksternal.

2. Kompetensi PT ANI adalah membuat produk kosmetik perawatan wajah dan pribadi.

3. Distinctive competencies PT ANI, diantaranya:

a. Tim marketing dan $\mathrm{R} \& \mathrm{D}$ handal.

b. Kemampuan membuat rancangan produk kosmetik dan personal care lebih cepat dibanding pesaing.

4. Pasar khusus (propitious niche) PT ANI adalah gerai produk alami, toko obat dan kosmetik, salon dan spa, dokter spesialis kulit dan perusahaan MLM, serta toiletris beberapa hotel di kota Bogor.

\section{Evaluasi Alternatif Strategi}

Matriks TOWS (Tabel 8) digunakan untuk menciptakan beberapa alternatif strategi perusahaan dalam menghadapi ancaman dan peluang eksternal, dengan mengimbangi kekuatan dan kelemahan internal yang dimiliki.

Tabel 8. Matriks TOWS

\begin{tabular}{|c|c|c|}
\hline EFAS & $\begin{array}{l}\text { Kekuatan (S) } \\
\text { - S1: Tim pemasaran andal } \\
\text { - S2: Kecepatan pengembangan produk } \\
\text { - S3: Tim R \& D yang kuat dan } \\
\text { berpengalaman dalam desain produk } \\
\text { dan proses } \\
\text { - S4: Hubungan kemitraan yang kuat } \\
\text { dengan beberapa pemasok bahan baku }\end{array}$ & $\begin{array}{l}\text { Kelemahan (W) } \\
\text { - W1: Keandalan fasilitas produksi } \\
\text { - W2: Prosedur pengendalian mutu } \\
\text { bahan baku } \\
\text { - W3: Efektivitas pengendalian mutu } \\
\text { fase prosesing } \\
\text { - W4: Level kapasitas produksi }\end{array}$ \\
\hline $\begin{array}{l}\text { Peluang (O) } \\
\text { - O1:Pertumbuhan ekonomi } \\
\text { Indonesia: peningkatan PDB dan } \\
\text { sektor PKRT } \\
\text { - O2: Pertumbuhan jumlah } \\
\text { penduduk Indonesia } \\
\text { - O3: Tren Gaya hidup masyarakat } \\
\text { - O4: Perkembangan teknologi } \\
\text { informasi (komputer dan internet) } \\
\text { - O5: Perkembangan teknologi } \\
\text { proses produksi kosmetik }\end{array}$ & $\begin{array}{l}\text { Strategi SO } \\
\text { 1. Menambah tenaga penjual freelance } \\
\text { untuk memperluas pasar khusus } \\
\text { diseluruh Indonesia (S1O1O2) }{ }^{c}\end{array}$ & $\begin{array}{l}\text { Strategi WO } \\
\text { 1. Perbaikan fasilitas produksi } \\
\text { berdasarkan perspektif pelanggan } \\
(\mathrm{W} 1 \mathrm{O} 1 \mathrm{O} 2)^{\mathrm{a})} \\
\text { 2. } \begin{array}{l}\text { Mengadakan sistem pengendalian } \\
\text { mutu }(\mathrm{W} 2 \mathrm{~W} 3 \mathrm{O} 4)^{\text {a) }}\end{array} \\
\text { 3. } \begin{array}{l}\text { Meningkatkan kapasitas untuk } \\
\text { memenuhi volume dan varian } \\
\text { produk yang diminta pelanggan } \\
(\mathrm{W} 4 \mathrm{O} 3)^{\text {a) }}\end{array}\end{array}$ \\
\hline $\begin{array}{l}\text { Ancaman (T) } \\
\text { - T1: Persyaratan izin industri } \\
\text { kosmetik } \\
\text { - T2: Pelemahan nilai tukar rupiah } \\
\text { terhadap dolar Amerika } \\
\text { - T3: Tingkat inflasi } \\
\text { - T4: Persyaratan sertifikat CPKB }\end{array}$ & $\begin{array}{l}\text { Strategi ST } \\
\text { 1. Mengadakan kontrak kerjasama dengan } \\
\text { pemasok untuk mendapatkan biaya } \\
\text { murah dan fasilitas tempo pembayaran } \\
(\text { S4T2T3) })^{\text {b) }}\end{array}$ & $\begin{array}{l}\text { Strategi WT } \\
\text { 1. Melakukan perbaikan fasilitas } \\
\text { produksi sesuai persyaratan CPKB } \\
(\text { W1T1T4) a) } \\
\text { 2. Meningkatkan kehandalan produk } \\
\text { melalui penerapan sanitasi dan } \\
\text { higiene pada personalia } \\
(\text { W2W3T1T4) a) }\end{array}$ \\
\hline
\end{tabular}

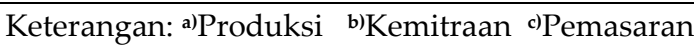




\section{Analisis Strategi Bisnis}

Analisi strategi bisnis PT ANI didahului analisis matriks IE untuk memetakan posisi perusahaan saat ini. Nilai total skor yang diperoleh pada Tabel EFAS dan IFAS diimplementasikan pada matriks $I E$, sehingga diperoleh hasil seperti Gambar 3. Perusahaan berada pada kuadran V yaitu bertahan dan memelihara pasar yang ada, dimana strategi yang paling tepat dijalankan adalah penetrasi pasar dan pengembangan produk.

Pengembangan produk merupakan contoh strategi diferensiasi yang menguntungkan. Berdasarkan strategi generik Porter (David, 2013), strategi bersaing yang cocok dijalankan untuk ukuran pasar yang sempit ini adalah strategi fokus diferensiasi (Gambar 4).

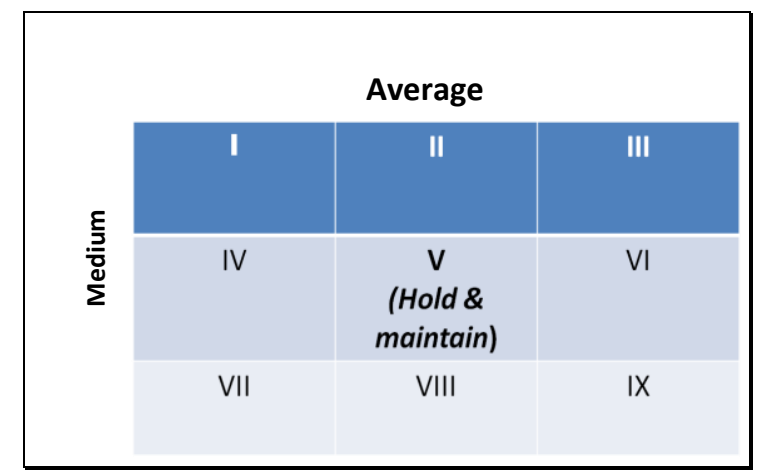

Gambar 3. Matriks IE dari PT ANI

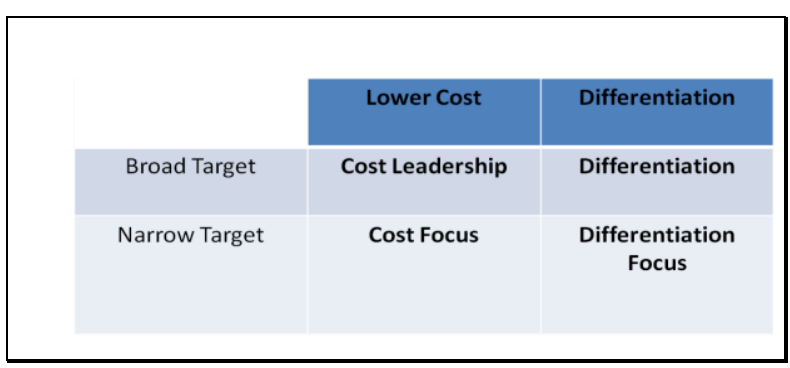

Gambar 4. Strategi Generik Porter (David, 2013)

\section{Perumusan Strategi Operasi}

Proses perumusan strategi operasi adalah bagian dari satu kesatuan proses manajemen strategik yang merupakan implementasi dari perumusan strategi pada tingkatan sebelumnya di level korporasi dan bisnis (Afriantoni 2013). Pada pasar kompetitif, strategi operasi perusahaan biasanya dirumuskan berdasarkan keunggulan kompetitif mereka. Strategi operasi yang efektif harus mempertahankan dan meningkatkan keunggulan kompetitif berdasarkan pada kemampuan sumber daya operasi perusahaan. Dengan memperhatikan kebutuhan pasar dan kinerja operasional pesaing adalah kunci untuk sukses dan kelangsungan hidup perusahaan dalam kompetisi (Anwar et al., 2014).

\section{Analisis Kebutuhan Pasar}

Model Slack dan Lewis menurunkan kebutuhan pasar dari kebutuhan konsumen, posisi pada pasar dan aktivitas yang dijalankan kompetitor. Produk PT ANI termasuk kategori green product cosmetics, karena terbuat dari bahanbahan alami yang ramah lingkungan. Beberapa merk terkenal untuk produk kosmetik sejenis diantaranya The Body shop, Mustika Ratu dan Sari Ayu. Oleh karena itu, PT ANI menyasar pasar ceruk untuk kategori green product cosmetics, yang tidak dimasuki oleh perusahaan industri kosmetik skala besar. Kebutuhan pasar ceruk selain rancangan formula kosmetik sesuai spesifikasi, juga jaminan keamanan dan manfaat penggunaan produk.

Kompetitor adalah perusahaan industri kosmetik skala kecil dan menengah yang tertarik untuk memasuki ceruk yang sama dan juga menjalankan model bisnis maklon atau Original Equipment Manufacture (OEM). Beberapa kompetitor telah memiliki fasilitas produksi yang modern dan sertifikat $\mathrm{CPKB}$, yang membuat pelanggan lebih tertarik bekerjasama dalam produksi kosmetik. PT ANI dapat unggul melalui rancangan formula kosmetik yang fleksibel dan dapat dilakukan lebih cepat dibanding kompetitor.

\section{Analisis Kapabilitas Sumber Daya Operasi}

Berdasarkan hasil analisis Value Chain dan VRIO, kapabilitas unggul sumber daya operasi perusahaan sebagai berikut;

1. Perusahaan memiliki hubungan kemitraan yang baik dengan beberapa pemasok yang mampu menyediakan beragam bahan baku, bahan pendukung dan bahan kemasan yang dibutuhkan untuk memproduksi beragam produk kosmetik yang diharapkan konsumen.

2. Perusahaan memiliki Tim R \& D yang kuat dan berpengalaman dalam membuat desain formula dan proses pembuatan sabun transparan dan produk kosmetik perawatan wajah/tubuh berbahan aktif alami.

\section{Prioritas Sasaran Kinerja Operasi}

Sasaran kinerja generik yang dapat dicapai fungsi operasi-produksi, untuk memuaskan pelanggan dan berkontribusi dalam peningkatan daya saing adalah:

1. Quality (mutu) merupakan sasaran kinerja yang harus dicapai fungsi operasi dalam 
rangka menghasilkan produk andal sesuai harapan pelanggan, yang pada akhirnya berdampak pada kontinuitas kerjasama produksi. Selain berpengaruh pada kepuasan pelanggan, mutu juga akan menciptakan proses yang stabil dan efisien.

2. Speed (kecepatan) merupakan kemampuan operasi dalam mengirimkan keseluruhan produk lebih cepat dari waktu yang telah ditentukan.

3. Dependebility (keandalan) merupakan kemampuan operasi dalam menyelesaikan pesanan secara tepat waktu (on time)

4. Flexibility (fleksibilitas) merupakan kemampuan operasi memodifikasi produk, menghasilkan beragam produk, merubah volume produksi, atau waktu pengiriman produk.

5. Cost (biaya) merupakan sasaran kinerja utama bagi perusahaan yang bersaing dengan harga murah.

Berdasarkan hasil analisis kebutuhan pasar dan kapabilitas sumber daya operasi-produksi, serta pengambilan keputusan dengan AHP, strategi operasi-produksi diprioritaskan memenuhi sasaran kinerja mutu $(0,454)$, keandalan $(0,270)$, fleksibilitas $(0,147)$, kecepatan $(0,082)$ dan biaya $(0,048)$.

\section{Prioritas Strategi Operasi}

Berdasarkan model bisnis dan kondisi internal perusahaan, maka PT ANI sebaiknya melakukan peningkatan kinerja operasi-produksi secara bertahap dengan pendekatan Total Quality Managemen (TQM) dan lean operation (operasi ramping). Peningkatan kinerja juga perlu disesuaikan dengan unsur CPKB yang belum diterapkan perusahaan. Peningkatan kinerja pada empat kategori keputusan (Gambar 5) adalah:

1. Strategi Kapasitas

a) Menyediakan sumber daya untuk mendukung kualitas dan menggunakan kualitas sebagai kriteria kinerja, diantaranya dengan meningkatkan fasilitas laboratorium untuk mendukung pengujian bahan baku dan bahan kosmetik di dalam proses.

b) Menyediakan sumber daya untuk meningkatkan level kapasitas secara keseluruhan, seperti memperluas ruang staging.

2. Strategi Jaringan Pasokan Perbaikan pada area ini difokuskan pada:

a) Membangun kualitas secara berkelanjutan dengan supplier bahan baku.

b) Menyediakan bahan baku berkualitas.

c) Meningkatkan efektifitas dan efisiensi dalam proses pembelian bahan baku, untuk perbaikan pasokan (kualitas, harga dan waktu pengiriman).

\section{Teknologi Proses}

Memastikan bahwa teknologi yang dipilih mendukung unsur Just In Time (JIT), yaitu fleksibilitas, kehandalan, mengurangi variabilitas dan mengadakan teknologi yang membangun mutu sepanjang proses produksi. Perbaikan pada area ini diantaranya mengadakan peralatan otomatis pada proses pemompaan dan pengisian bahan.

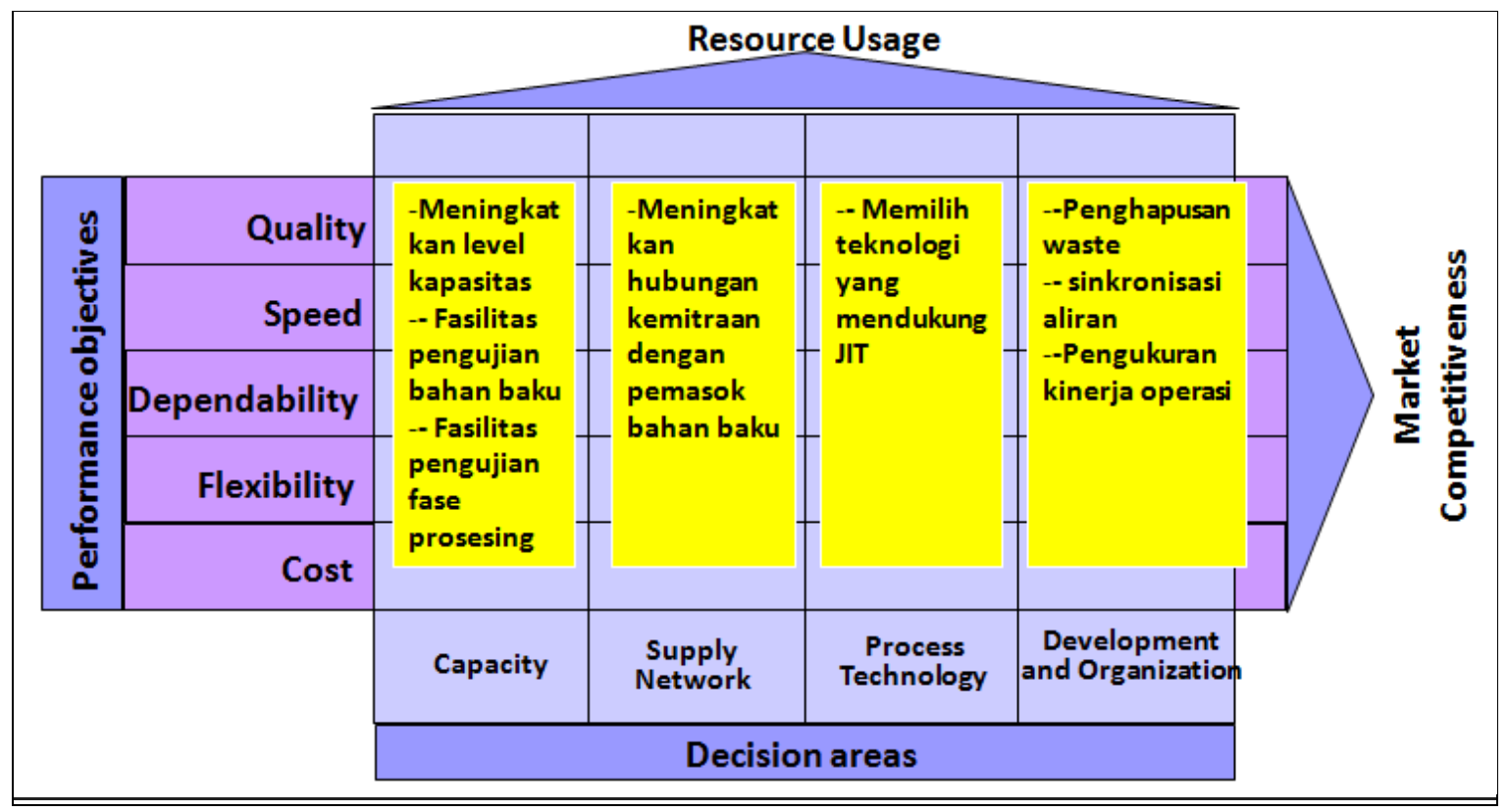

Gambar 5. Matriks strategi operasi PT ANI 
4. Pengembangan dan Organisasi

Perbaikan penting pada area ini dapat dilakukan dengan menggunakan pedoman CPKB. Dari empat puluh delapan unsur CPKB, perusahaan telah memenuhi 24 unsur. Melihat kapasitas organisasi, terutama pemegang keputusan, perusahaan mampu untuk memenuhi sisanya. Hal ini berkenaan investasi untuk mendukung pengembangan perusahaan.

Berdasarkan hasil pembobotan dengan metode AHP, top management dapat merencanakan perbaikan kinerja operasi-produksi dengan urutan prioritas berikut:

1. Perbaikan pada area teknologi proses menghasilkan bobot 0,425 .

2. Perbaikan pada area jaringan pasokan menghasilkan bobot 0,235.

3. Perbaikan pada area kapasitas menghasilkan bobot 0,206.

4. Perbaikan pada area pengembangan dan organisasi menghasilkan bobot 0,133 .

\section{Implikasi Hasil Penelitian}

1. Dalam lingkungan pasar global, IKM kosmetik perlu melakukan evaluasi terhadap misi dan strategi yang dijalankan.

2. IKM kosmetik perlu melakukan perencanaan peningkatan kinerja operasi-produksi yang berisi keputusan struktural dan infrastruktur pada area teknologi proses, jaringan pasokan, kapasitas dan pengembangan organisasi. Hal ini dimaksudkan agar IKM dapat menghasilkan produk berstandar internasional dan sumber daya dapat bertahan dalam jangka panjang.

\section{KESIMPULAN}

1. Misi PT ANI menghasilkan produk kosmetik perawatan wajah dan pribadi berbahan aktif alami yang aman dan bermutu untuk menangkap target pasar khusus di dalam dan luar negeri.

2. Berdasarkan analisis matriks IE, perusahaan berada pada kuadran 5, yaitu bertahan dan memelihara pasar yang ada. Pada fase ini, perusahaan dapat menjalankan strategi bersaing diferensiasi fokus.

3. Sasaran kinerja fungsi operasi-produksi diprioritaskan pada mutu $(0,454)$, keandalan $(0,270)$, fleksibilitas $(0,147)$, kecepatan $(0,082)$ dan biaya $(0,048)$.
4. Strategi operasi-produksi diprioritaskan pada teknologi proses $(0,425)$, jaringan pasokan $(0,235)$, kapasitas $(0,206)$ serta pengembangan dan organisasi $(0,133)$.

5. Pembangunan sumber daya dan proses operasi-produksi kosmetik adalah dengan mengadakan peralatan otomatis pada proses pemompaan dan pengisian bahan, melakukan perbaikan mutu bahan baku komoditas dari pemasok, memperluas ruang staging dan meningkatkan keandalan laboratorium, serta menerapkan sistem manajemen mutu berpedoman CPKB.

\section{DAFTAR PUSTAKA}

Acharyulu, SG., K. Venkata Subbaiah dan K. Narayana. 2015. Value Chain Model For Steel Manufacturing Sector: A Case Study. International Journal of Managing Value and Supply Chains (IJMVSC) Vol. 6, No. 4:45-53.

Afriantoni. 2013. Analisis Potensi Strategi Operasi untuk Meningkatkan Daya Saing Industri Reparasi Kapal pada Galangan Kapal Nasional. Seminar Nasional Industri dan Teknologi, Vol. 2, No. 1:63-73. FTK ITS, Surabaya.

Anwar, BS., T. Alhabsji dan Djumahir. 2014. The Relationship Between Operations Strategy and Competitive Strategy In Improving Firm Performance: A Literatur Review. International Journal of Business and Management Invention Volume 3 Issue 7 PP.05-12.

David, FR. 2011. Strategic Management Concepts and Cases. (13th ed.) New Jersey: Pearson Education, Inc.

Fadun, SO. 2014. Strategic Management, an Organisational Risk Management Framework: Case Study of Guaranty Trust Bank Plc. International Journal of Academic Research in Accounting, Finance and Management Sciences Vol. 4(2):51-61.

[Kemenperin] Kementrian Perindustrian. 2014. Indonesia Lahan Subur Industri Kosmetik [Berita Industri]. [diacu 17 Oktober 2014]. Tersedia dari : http://kemenperin.go.id/ artikel/5897/Indonesia-Lahan-SuburIndustri-Kosmetik.

[Kemenperin] Pusat Komunikasi Publik Kementrian Perindustrian. 2015. Rencana Induk Pembangunan Industri Nasional 2015-2035. Jakarta (ID). 
[MENKESRI] Menteri Kesehatan Republik Indonesia. 2010. Peraturan Menteri Kesehatan No. 1175/Menkes/Per/VIII/2010 Tahun 2010 tentang Izin Produksi Kosmetika. Jakarta (ID): MENKESRI.

[MENKESRI] Menteri Kesehatan Republik Indonesia. 2010a. Peraturan Menteri Kesehatan No. 1176/Menkes/Per/VIII/2010 Tahun 2010 tentang Izin Produksi Kosmetika. Jakarta (ID): MENKESRI

[MENKESRI] Menteri Kesehatan Republik Indonesia. 2010. Peraturan Menteri Kesehatan No. 1175/Menkes/Per/VIII/2010 Tahun 2010 tentang IzinProduksi Kosmetika. Jakarta (ID): MENKESRI

Slack, N and M. Lewis. 2011. Operations Strategy, $3^{\text {rd }}$ edition. Prentice Hall, Pearson Education Limited, England.

Sulistyo, R., A. Soedjarno and MT. Simatupang. 2011. Operation Strategy Formulation:
Shifting from Grasberg Open-Pit Surface Mining to Underground Mining [Jurnal]. International Research Journal of Business Studies Vol 4 No. 01 : 21-48. Prasetiya Mulya Business School, Jakarta.

Tiyanto, TR dan RH. Mustamu. 2013. Analisis Deskriptif Strategi Bersaing pada Perusahaan Kosmetik [Internet]. Jurnal AGORA Vol 1(1).

Wandrial, S. 2011. Analisis Internal Perusahaan (Strength \& Weakness) Menggunakan Konsep Resource-Based View of the Firm dengan Kerangka VRIO. Binus Business Review Vol 2(2):627-637.

Wheelen, TL., \& Hunger, JD. 2012. Concepts in Strategic management and Business Policy. (13th ed.) New Jersey: Pearson Education, Inc. 